\title{
Efficacy and efficiency of a new therapeutic approach based on activity-oriented proprioceptive antiedema therapy (TAPA) for edema reduction and improved
} occupational performance in the rehabilitation of breast cancer-related arm lymphedema in women: a controlled, randomized clinical trial

María Nieves Muñoz-Alcaraz 1,2, Luis Ángel Pérula-de-Torres ${ }^{1,2}$, Jesús Serrano-Merino 1,2, Antonio José Jiménez-Vílchez ${ }^{3}$, María Victoria Olmo-Carmona ${ }^{4}$, María Teresa Muñoz-García ${ }^{4}$, Cruz Bartolomé-Moreno ${ }^{5,6}$, Bárbara Oliván-Blázquez ${ }^{5,7^{*}}$ (D) and Rosa Magallón-Botaya ${ }^{5,7}$

\footnotetext{
Abstract

Background: Breast cancer (BC) is a major public health issue. More than one out of five women treated for breast cancer will develop lymphedema in an upper extremity. Current evidence advocates transdisciplinary oncological rehabilitation. Therefore, research in this area is necessary since limited consensus having been reached with regard to the basic essential components of this rehabilitation.

Consensus has, however, been reached on the use of decongestive lymphedema therapy (DLT), but due to a lack of tests, the necessary dosages are unknown and its level is moderately strong.

This study attempts to verify both the efficacy of activity-oriented proprioceptive antiedema therapy (TAPA), as compared to conventional treatments such as DLT or Complex Physical Therapy (CPT), as well as its efficiency in terms of cost-effectiveness, for patients affected by breast cancer-related arm lymphedema.

(Continued on next page)
}

\footnotetext{
* Correspondence: bolivan@unizar.es; barbaraolivan@gmail.com

5 Institute for Health Research Aragon (IIS Aragon), Zaragoza, Spain

7 University of Zaragoza, Zaragoza, Spain

Full list of author information is available at the end of the article
}

(c) The Author(s). 2020 Open Access This article is licensed under a Creative Commons Attribution 4.0 International License, which permits use, sharing, adaptation, distribution and reproduction in any medium or format, as long as you give appropriate credit to the original author(s) and the source, provide a link to the Creative Commons licence, and indicate if changes were made. The images or other third party material in this article are included in the article's Creative Commons licence, unless indicated otherwise in a credit line to the material. If material is not included in the article's Creative Commons licence and your intended use is not permitted by statutory regulation or exceeds the permitted use, you will need to obtain permission directly from the copyright holder. To view a copy of this licence, visit http://creativecommons.org/licenses/by/4.0/. The Creative Commons Public Domain Dedication waiver (http://creativecommons.org/publicdomain/zero/1.0/) applies to the data made available in this article, unless otherwise stated in a credit line to the data. 
(Continued from previous page)

Methods: Controlled, randomized clinical trial with dual stratification, two parallel arms, longitudinal and single blind. 64 women with breast cancer-related arm lymphedema will take part in the study. The experimental group intervention will be the same for stage I and II, and will consist of neuro-dynamic exercises oriented to the activity, proprioceptive neuromuscular facilitation activities and proprioceptive anti-edema bandaging. The control group intervention, depending on the stage, will consist of preventive measures, skin care and exercise-prescribed training in the lymphedema workshop as well as compression garments (Stage I) or conservative Complex Decongestive Therapy treatment (skin care, multi-layer bandaging, manual lymphatic drainage and massage therapy) (Stage II).

Results: Sociodemographic and clinical variables will be collected for the measurement of edema volume and ADL performance. Statistical analysis will be performed on intent to treat.

Discussion: It has been recommended that patient training be added to DLT, as well as a re-designing of patient lifestyles and the promotion of health-related aspects. In addition, clinical trials should be undertaken to assess neural mobilization techniques and proprioceptive neuromuscular facilitation should be included in the therapy. Cohesive bandaging will also be performed as an early form of pressotherapy. The proposed study combines all of these aspects in order to increased comfort and promote the participation of individuals with lymphedema in everyday situations.

Limitations: The authors have proposed the assessment of the experimental treatment for stages I and II. One possible limitation is the lack of awareness of whether or not this treatment would be effective for other stages as well as the concern for proper hand cleansing during use of bandages, given the current COVID-19 pandemic situation.

Trial registration: This trial was registered in ClinicalTrials.gov (NCT03762044). Date of registration: 23 November 2018. Prospectively Registered.

Keywords: Occupational therapy (OT), Breast cancer (BC) - lymphedema (L), Activity-oriented proprioceptive antiedema therapy (TAPA in Spanish), Health-related quality of life (HRQOL), Complex decongestive therapy (CDT)

\section{Background}

Breast cancer $(\mathrm{BC})$ is a major public health issue, being the most common global cause of cancer-related deaths in females and the second most common form of cancer, with over 2 million new cases occurring in 2018 [1]. BC survival rates have improved notably over the past 20 years (survival from this type of tumor increases by $1.4 \%$ annually) [2]. BC survivors face challenges in their activities of daily living (ADL), as a result of both the illness and the subsequent treatments undertaken. These challenges include altered sensory and pain functions and neuromusculoskeletal and movement-related alterations, as well as alterations of the skin and related structures. These symptoms tend to continue for extended periods of time and therefore, BC survival has been categorized as a chronic illness with new challenges arising for rehabilitation services [3, 4].

It is estimated that more than one out of every five women treated for BC will develop lymphedema in an upper extremity (20\% in 6 months, $36 \%$ in 1 year and $54 \%$ within 36 months). The most relevant risk factors are the number of lymph nodes excised in surgery, radiation therapy and obesity. This is a chronic and progressive disorder that causes edema, skin changes (which may cause fibrosis and deformity), pain, sensitivity alterations, fatigue, limitations in joint rotation, recurrent infections, an inability to independently carry out ADL, low self-esteem, etc. Although it has been recognized for years now, consensual treatment dose programs have yet to be established [5].

Tertiary prevention in $\mathrm{BC}$ attempts to combat the consequences of this illness. It includes aspects such as rehabilitation, relapse prevention, early diagnosis of second malignancies, management of late complications through treatments and emotional support. This type of assistance has been traditionally presented for some time now in specialized health care, but it is currently becoming an increasing primary care responsibility $[6,7]$.

Rehabilitation of $\mathrm{BC}$ patients is intended to ensure their social integration and participation. Current evidence suggests the importance of transdisciplinary oncological rehabilitation. Therefore, research in this area is essential [8], since it is of great importance and quite different from the treatment phase and should include physical and occupational therapies (OT) [9]. Numerous rehabilitation models currently exist, but consensus has not been reached as to the basic necessary components of integral rehabilitation for cancer survivors [10, 11]. The regional government of Andalusia (Spain) designed an Integrated Palliative Care Process (IPC) for BC [12], which includes aspects to be carried out during the rehabilitation process, including lymphedema therapy, whose implementation has been quite disparate in the distinct provinces of the region. The literature also finds 
follow up recommendations based on risk factors and care level [7].

Consensus has been reached with regard to the utility of decongestive lymphedema therapy [13] but tests have yet to determine the optimal treatment dosage to be used and the level of evidence regarding its effectiveness in lymphedema treatment is only moderately strong, due to a limited number of randomized trials conducted with control groups, a lack of well-controlled interventions and measurements of precise volume, mobility or function and quality of life $[5,14,15]$. Similarly, the prescription of compression garments for lymphedema is quite varied and may be due to the lack of underlying evidence to inform on the treatment [16-18].

Evidence also suggests that complete and effective post-operative $\mathrm{BC}$ rehabilitation should also include patient self-control (empowerment), focus on the redesigning of their life style and include health promotion aspects [8, 19-21].

Studies have also confirmed that women with lymphedema and pain following $\mathrm{BC}$ may present alterations in their neuro-mechanical sensitivity [22] and neuropathic pain, as a result of nerve compression, or peripheral neuropathy induced by chemotherapy [2]. So, clinical trials should be carried out to assess neural mobilization techniques that focus on the functionality of the upper limbs [23], based on the clinical neural mobilization mechanism to reduce the intra-neural edema [24].

Studies have suggested the incorporation of proprioceptive neuromuscular facilitation elements (PNF) with traditional methods of manual lymphatic drainage (MLD), to facilitate the treatment process for lymphedema patients, since they induce powerful synergic effects on edema volume, range of motion (ROM) of the shoulder, pain and depression [25]. Their independent or combination use with laser treatment has also been suggested, since improvements were also found in these variables and even in the rate of blood circulation in the underarm [26]. Also, in a study in which bandaging was not used, CDT was combined with PNF and respiration, reducing the lymphedema and also improving ROM [27], which could potentially improve activity performance, participation level and thus, quality of life [14, 28].

In response to the evidence regarding the use of the Coban ${ }^{\oplus} \mathrm{M}$ bandage as an early precursor to pressotherapy in the rehabilitating treatment of lymphedema to reduce prolonged edema (the causal agent of multiple complications and functional loss) [18, 29-31], we propose the possibility of testing the effectiveness of similar bandages, but ones that avoid compressive syndromes, decrease pain and edema, promote the development of ADL and improve the treatment's costeffectiveness [32, 33]. We suggest combining its use with the three previously mentioned techniques (healthcare education/patient training, neuro-dynamic activities geared to neuro-muscular use and proprioceptive neuromuscular facilitation oriented towards ADL) and which, collectively, are referred to as "TAPA" (in Spanish, Activity-oriented proprioceptive antiedema therapy).

Given the consensus for conservative lymphedema treatment, such as Complex Decongestive Therapy (CDT) or Complex Physical Therapy (CPT), we believe that comparison with our TAPA treatment should be made with this type of treatment.

This study attempts to assess the effectiveness of TAPA, in terms of cost-effectiveness, calculating costs of material and human resources. Current expenditure on bandaging materials for CDT is at least double that which would be spent on TAPA, since, instead of multilayers (usually two or three) only one is used here, and patients may require an annual prescription for compression garments, included in the catalogue of orthoprosthetic products of the Andalusian Health Service [34] and the use of these is minimized by TAPA. Personnel expenses for CDT are for approximately 60 min per treatment, using an individual approach formula, while TAPA sessions are approximately $30 \mathrm{~min}$, and are carried out individually, with the possibility of a group approach. This, as well as the effectiveness of the treatment in terms of measurement of the reduced volume of the lymphedema, will improve the functionality of the upper extremity, during the performance of daily living activities (occupational) and therefore, in HRQOL.

\section{Hypotheses and objectives}

Hypothesis: Activity-oriented proprioceptive antiedema therapy is more cost-effective than standard treatment.

\section{Objectives}

This study aims to verify both the efficacy of the new therapy (TAPA) versus conventional treatment, as well as its efficiency in terms of cost-effectiveness, in patients suffering from Breast Cancer-Related Arm Lymphedema (BCRAL).

\section{Specific objectives}

- To measure the decrease in volume of the affected limb treated with TAPA and the maintenance of the effect over time ( 1 month and 3 months).

- To evaluate its effect on the performance of activities of daily living (ADL).

- To evaluate its effect on health-related quality of life (HRQOL).

- To determine efficiency in terms of simplicity of handling and economy of the anti-edema bandage technique used in the TAPA group. 


\section{Methods}

\section{Design}

Controlled clinical trial, randomized by stratification in two gradients, with two parallel arms, longitudinal and single blind. To measure the efficiency of the new treatment, a cost-effectiveness study will be performed [34-36]

\section{Study subjects}

The study population will be females who were treated for breast cancer, diagnosed with Breast Cancer-Related Arm Lymphedema (BCRAL), referred to the UGC Rehabilitation Inter-levels of the Reina Sofía Hospital-Córdoba and Guadalquivir health district, from either the multi-disciplinary breast department of Specialized Care or the Primary Care teams, whose flow diagram of referrals to rehabilitation, both in-hospital and at home, for the treatment of post-mastectomy lymphedema and for individual or group treatment, is described in the Guide to Rehabilitation and Physical Therapy Procedures in Primary Care [37].

\section{Selection criteria \\ Inclusion criteria}

- Women, treated for BC with a diagnosis of level I and II BCRAL, according to stratification of the Work Group of the 11th International Congress of Lymphology [38], which establishes:

- Stage 1 or mild: difference in the circometry of less than $4 \mathrm{~cm}$ (in volume 10-25\%) with respect to the healthy arm.

- Stage 2 or moderate: difference in the circometry of between 4 and $6 \mathrm{~cm}$ (in volume 25-50\%) with respect to the healthy arm.

- Patient's informed consent.

\section{Exclusion criteria}

- Health problems, illnesses or disabilities that prevent them from participating in the intervention.

- Other pathologies affecting the HRQOL: untreated cardiac, renal or respiratory insufficiency.

- Bi-lateral lymphedema.

\section{Participant inclusion}

Department specialist in rehabilitation invites the patient to participate, informing them of the purposes of the research and its procedures.

If they decide to participate, they should sign the Informed Consent, which shall be kept by the researcher.
Once the subject is included in the study, they will be assigned a study protocol number, which will serve to identify them in all of the study documents. This is a unique identification number created with an algorithm based on the center where they came from, their initials and date of birth, which shall subsequently be encrypted in an 8-digit number in the coordinating center. The codes shall be delivered to each researcher at the start of the study.

\section{Sample size}

It is agreed that a decrease in the volume of the clinically relevant lymphedema may be established at $150 \mathrm{ml}$. (minimal detectable value) [39], 20\% with respect to the baseline. Based on data from the literature on means and standard deviations [25, 40], for an alpha error of 0.05 and a statistical power of 0.80 , the necessary sample size would be 29 subjects per group (calculation performed with EPIDAT 4.2). It is assumed that the standard treatment effect in the control group will lead to a reduction in arm volume by an average of $5 \%$, the treatment effect in the experimental group will cause an average reduction in arm volume of $20 \%$, and the standard deviation will be similar in both groups, approaching $20 \%$ [41]. Taking into account the dropout rate of $10 \%$ in each group, the corrected sample size is 64 patients, randomly assigned to two groups with 32 patients each.

\section{Randomization}

Subjects were selected randomly using stratified random selection, in stages I or II, according to stratification of the Work Group of the 11th International Congress of Lymphology. Following capture and recruitment, participants were randomly assigned to one of the two groups (experimental or control).

\section{Random allocation and concealment of allocation}

The random assignment sequence was created using EPIDAT, 3.1 statistical software, which stratifies the patients according to lymphedema stage, with a 1:1 ratio, using blocks having a random size of 4 . The assignment sequence was hidden from the researcher assessing the participants through sequentially numbered envelopes that are opaque, sealed and stapled.

Allocation will be carried out by a department specialist in the Physical Medicine and Rehabilitation department.

\section{Sampling technique}

Consecutive sampling. Patients who comply with the selection criteria will be invited to participate in the study as they are identified and captured by the field researcher entrusted with this task. 
Sampling will be carried out by a department specialist from the Physical Medicine and Rehabilitation department.

\section{Blinding}

Following the assignment of the interventions, these results will be hidden from the evaluator, who is a final year medical resident specializing in Physical Medicine and Rehabilitation (AJ), who will also monitor the data and data analysts (LA and J), who will not receive information on which of the treatments corresponds to the distinct data.

The party responsible for the random assignment and participant capture will inform the evaluator and the participants of the distinct dates of results assessment for each of them, and they will be reminded of the same and will have this information confirmed (or modified) via telephone on the preceding days.

Participants will attach the protocol follow-up sheet, registering any adverse effects, if occurring, as well as drop outs, losses and causes for the same.

Study revision by part of the research team is ongoing, through the use of the new technologies and a formal quarterly meeting.

\section{Study variables and measurement instruments}

The study variables are shown in Tables 1, 2, 3 .

\section{Information sources}

A data collection notebook/form will be created, which will be accompanied by a procedures manual.

The following instruments will be used for the measurement (Table 2), comparison and treatment of dependent variables:

\section{Statistical analysis}

Analysis is performed for intent to treat. Data lacking after the basal measurements are replaced using the last available observation. Quantitative and qualitative variables will be described as usual (mean, standard deviation; proportions). An analysis of basal comparability of the sociodemographic and clinical variables (Table 1) will be carried out between both treatment groups. Then, a bivariate analysis will be conducted, previously verifying that the quantitative variables follow a normal distribution, using the Kolmogorov-Smirnov or ShapiroWilk tests, in which case, a repeated measures ANOVA is carried out (Mixed Models), to analyze the profile of patients from the basal measurement (24-72 $\mathrm{h}$ before treatment onset), after completing 10 sessions and one and 3 months later. If the variables do not follow a normal distribution, non-parametric tests will be used (Friedman's test). In addition, a multivariate analysis will be performed, as well as a survival analysis, Cox regression or multiple linear regression, taking into account the examined sociodemographic and clinical covariables resulting statistically significant following the bivariate analysis, for their inclusion in the model or to be controlled for, given their potential confounding effect. The main dependent variable will be the reduction of volume of the affected extremity. Statistical analysis will be performed using the Statistical Package for the Social Sciences (SPSS v.17). Statistical significance values will be those normally used $(p<0.05)$ and bilateral contrasts will be carried out. To evaluate effectiveness, a comparative analysis of economic costs of both treatments will be performed.

\section{Interventions}

Following capture and recruitment, participants were randomly assigned to one of the two groups.

Both groups will receive a 3-h long healthcare education workshop on lymphedema (Lymphedema workshop), led by a department specialist in the Physical Medicine and Rehabilitation Dept. of the Clinical Interlevel Rehabilitation Management Area (MV), and offering basic knowledge on the physiopathology of lymphedema, identification of symptoms, preventive skin care measures, ADL orientation, including physical activity and recommendations for neck and arm anti-edema exercises and postures to be carried out at least once daily.

The interventions used for the Experimental group will be the same for stage I and II, and will receive 10 sessions ( 2 per week), of $30 \mathrm{~min}$ each, led by an Occupational Therapist from the Córdoba and Guadalquivir health district $(\mathrm{MN})$ :

- 10-min neuro dynamics oriented to the activity.

-10-min proprioceptive neuromuscular facilitation activities.

-10-min proprioceptive anti-edema bandaging, including patient and/or caretaker instructions for placement, as well as assistance on techniques to use for performing everyday activities.

Proprioceptive anti-edema bandaging will be placed after carrying out the neuro dynamic and neuromuscular facilitation activities. Cohesive elastic bandages will be used, containing a high content of cotton and anti-slip.

The Control group intervention, depending on the stage, will be led by a physiotherapist from the Reina Sofía Hospital in Córdoba, and will consist of:

Stage I:

- Preventive measures, skin care and exercise prescribed by the rehabilitation physician and training in the lymphedema workshop.

- Compression garments.

-Duration of 5 weeks.

Stage II:

Ten sessions of $60 \mathrm{~min}$ of conservative treatment of Complex Decongestive Therapy (the literature does not 
Table 1 Independent study variables and their measurement instruments

\begin{tabular}{|c|c|}
\hline $\begin{array}{l}\text { INDEPENDENT VARIABLES } \\
\text { (Sociodemographic and clinical variables) }\end{array}$ & $\begin{array}{l}\text { MEASUREMENT INSTRUMENTS (to be filled in with information from interviews and } \\
\text { clinical records) }\end{array}$ \\
\hline - ID: Identification number for the study $(1,2,3 \ldots)$ & ID: \\
\hline - Age. & $\begin{array}{l}\text { Date of bird _/_- } \\
\text { _ years old }\end{array}$ \\
\hline - Group (Treatment carried out): & TAPA / standard. \\
\hline - Work activity: & $\begin{array}{l}\text { Working (Which?) } \\
\text { /Retired/Unemployed/Others (Which?) }\end{array}$ \\
\hline - Menstrual situation: & Pre-menopausal/Post-menopausal \\
\hline - Laterality: & Right/ left/Both \\
\hline $\begin{array}{l}\text { - Body mass index (BMI): } \\
\text { - Obesity: }\end{array}$ & $\begin{array}{l}\text { BMl: height/weight }{ }^{2} \\
\text { yes }(\mathrm{BMI}>=30) / \mathrm{no}(\mathrm{BMl}<30)\end{array}$ \\
\hline - AHT (Arterial hypertension): & Yes (> = 120/80 mmHg/take medication) / no (< 120/80 mmHg) \\
\hline - DLP (Dyslipidemia): & Yes (> = $200 \mathrm{mg} \mathrm{dl} /$ take medication) / no (<200 mg/dl) \\
\hline - DM (Diabetes): & Yes (> = $126 \mathrm{mg} \mathrm{dl} /$ take medication) / no (<126 mg/dl) \\
\hline - Heart disease: & Yes / no \\
\hline - Kidney failure: Yes / no & Yes / no \\
\hline - Vascular disease: Yes /no & Yes / no \\
\hline - Thyroid disease: Yes / no & Yes / no \\
\hline - Pacemaker: Yes / no & Yes / no \\
\hline - Electro-stimulator: Yes /no & Yes / no \\
\hline - Date of $B C$ diagnosis & I_ \\
\hline - Date of lymphedema diagnosis & - \\
\hline - Stage: & ।, II \\
\hline - Edema location: & $\begin{array}{l}\text { Hand }(H) / \text { Forearm }(F) / A r m(A) / \text { Breast } \\
H+F / H+F+A / F+A / C o m p l e t e / \text { Others (this category should be thoroughly considered) }\end{array}$ \\
\hline - Breast: & Right/ left \\
\hline - Date of surgical intervention: & - \\
\hline $\begin{array}{l}\text { - Type of tumor: } \\
\text { - Intervention type: Conservative/mastectomy }\end{array}$ & $\begin{array}{l}\text { ductal infiltrating/in situ/ lobular/ inflammatory/tubular/other (which?): } \\
\text { Conservative/mastectomy }\end{array}$ \\
\hline - Axillary surgery: & sentinel ganglion biopsy (SGB)/ lymphadenectomy /Both/none \\
\hline - No. of excised ganglia: & $\mathrm{N}^{\circ}$ \\
\hline - No. positive ganglia: & $\mathrm{N}^{\circ}$ \\
\hline - Complications: & Infection/ hematoma/ seroma/nerve lesion/Axillary web syndrome \\
\hline - Chemotherapy: & Yes / no \\
\hline - Radiotherapy: & Yes / no \\
\hline - Hormone therapy: & Yes / no \\
\hline - Immunotherapy: & Yes / no \\
\hline - Breast reconstruction: & $\begin{array}{l}\text { Yes / no } \\
\text { Yes: } \\
\text { - Type of reconstruction: Prosthesis/back/ abdomen } \\
\text { - Reconstruction time: Immediate/ deferred }\end{array}$ \\
\hline - Date of symptom onset: & -1 \\
\hline - Lymphedema: & Right/ left \\
\hline
\end{tabular}

refer to specific protocols to quantify session duration, therefore, expert opinions based on everyday practice were used as a reference):
-Skin care.

-Multi-layer bandaging.

-Manual lymphatic drainage. 
Table 2 Primary dependent study variables and their measurement instruments

\section{PRIMARY DEPENDENT VARIABLES}

- Treatment adherence:

- Skin hydration:

- Skin lesions:

- Nail lesions: Yes / no

- Induration / Fibrosis: Yes / no

- Pitting edema: Yes / no

- Stemmer: Yes / no

\section{- Pain:}

- Heaviness:

- Tension:

- Shoulder joint rotation: of volumetric):

- Difference in volume in \% between both extremities:

- Volumetric in $\mathrm{ml}$ :

- Function of the upper limb/activity performance.
- Degree of lymphedema (according to \%

- Volumetric \%:

\section{MEASUREMENT INSTRUMENTS/INTERPRETATION OF RESULTS}

- yes/no

Calculation of the percentage of treatment compliance for therapeutic adherence. $\mathrm{PC}=$ number of activities performed by patient/number of activities prescribed by the therapist * 100 . If PC is equal to or over $80 \%$, it is considered that there was good treatment adherence. If less, no.

-Physical state of the limb (inspection and palpation of the affected area). Photographs will be taken of the limb [42].

Normal/ dry/sweating

Yes / no

Yes / no

Yes / no

Yes / no

Yes / no

-Visual analogue scale (VAS), where 0 is no pain, heaviness or tension and 10 is maximum pain, heaviness or tension.

VAS $0-10$

VAS $0-10$

VAS $0-10$

Degrees with goniometer: Flexion____Abduction__External rotation___

-Volume, through circometry (manual measurement of perimeters of the limbs with a tape measure, the value of the volume is approximate and volume is calculated using the Kuhnke formula $\mathrm{Vol}=(\mathrm{C} 12+\mathrm{C} 22+\ldots \mathrm{Cn} 2) / \pi))[43-45]$.

_Grade 1 or mild: difference in circometry less than $4 \mathrm{~cm}$ (in volume 10-25\%) with respect to the healthy arm.

_Grade 2 or moderate: difference in circometry between 4 and $6 \mathrm{~cm}$ (in volume 25-50\%) with respect to the healthy arm.

$\mathrm{Vol}=\ldots$

$\mathrm{D}=\overline{\%}$

$\mathrm{Vol}=\ldots \mathrm{ml}$

*an edema reduction of $150 \mathrm{ml}$ over the basal value is required in order to be considered clinically relevant

- Value of Quick Disabilities of the Arm, Shoulder and Hand (Quick DASH) [21], with transcultural, reliability, validity and sensitivity adaptation to changes of its extended version in 2006 [46, 47].

- Quick DASH value = _\% (the result is calculated as a percentage, the higher the obtained result, the greater the disability or symptom)

- Treatment costs
Sum of expenses:

-Prescription of compression garment:

Yes (specify type and cost

- Type of bandaging used:

proprioceptive / multi-layer (number of rolls used per price of each of the same)

- Total number of treatment hours with therapist:

5/10/other (which:
) (number of hours used per professional hour price)

Table 3 Study secondary dependent variable and its measurement instruments

\section{SECONDARY DEPENDENT VARIABLE}

-Health related quality of life (HRQOL).

\section{MEASUREMENT INSTRUMENTS/INTERPRETATION OF RESULTS}

- Value of Upper Limb Lymphedema 27 (ULL-27), specific instrument for patients with Breast Cancer-Related Arm Lymphedema, transculturally adapted and validated in its Spanish version in 2016 [48]. (The result is calculated as a percentage of social, physical and psychological dimensions in which the higher the result obtained, the greater the disability or symptom/poorer the $\mathrm{HRQOL}$ ).

- Health Questionnaire EQ-5D-5L by EuroQol Group, generic and standardized instrument used to describe and value the HRQOL of a group or population and validated in Spain by Badia X. et al. in 1999 [49]. Numeric value between 3 and 45, in which the higher the score, the poorer the HRQOL. 
-Massage therapy (22).

Participants will be notified that during the intervention and follow-up period, they may not undertake other treatment for their BCRAL and, in the case of being subject to experimental treatment and not achieving the expected edema reduction, they may complete standard treatment upon study completion.

To analyze the patient profile from the basal measurement (24-72 $\mathrm{h}$ prior to treatment onset), until immediately following completion of the 10 sessions and one and 3 months later (Fig. 1).

\section{Study duration}

The anticipated study duration is 18 months, which may be modified based on the patient recruitment period. In Fig. 2, Gantt's study diagram is shown.

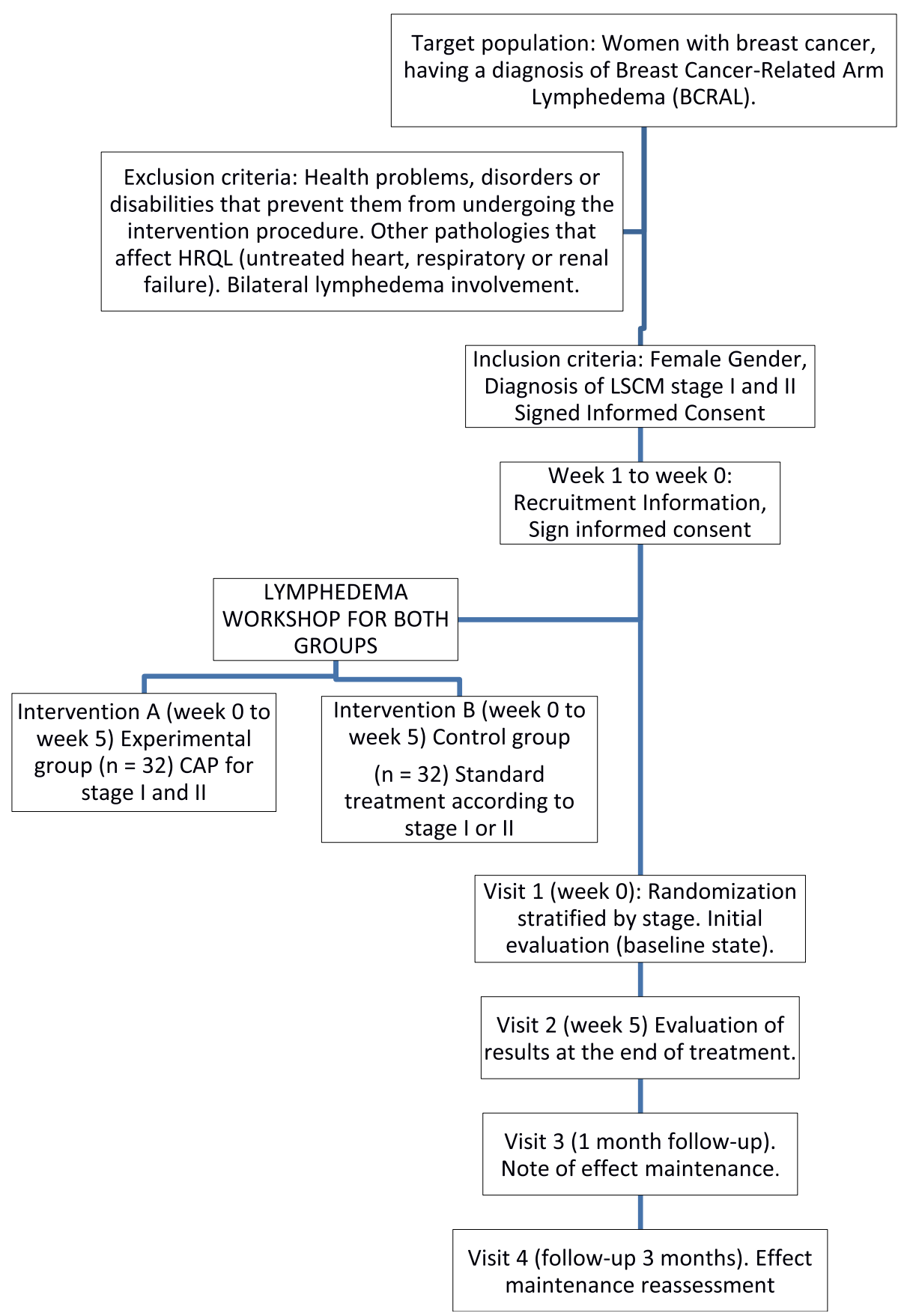

Fig. 1 Study flow design 


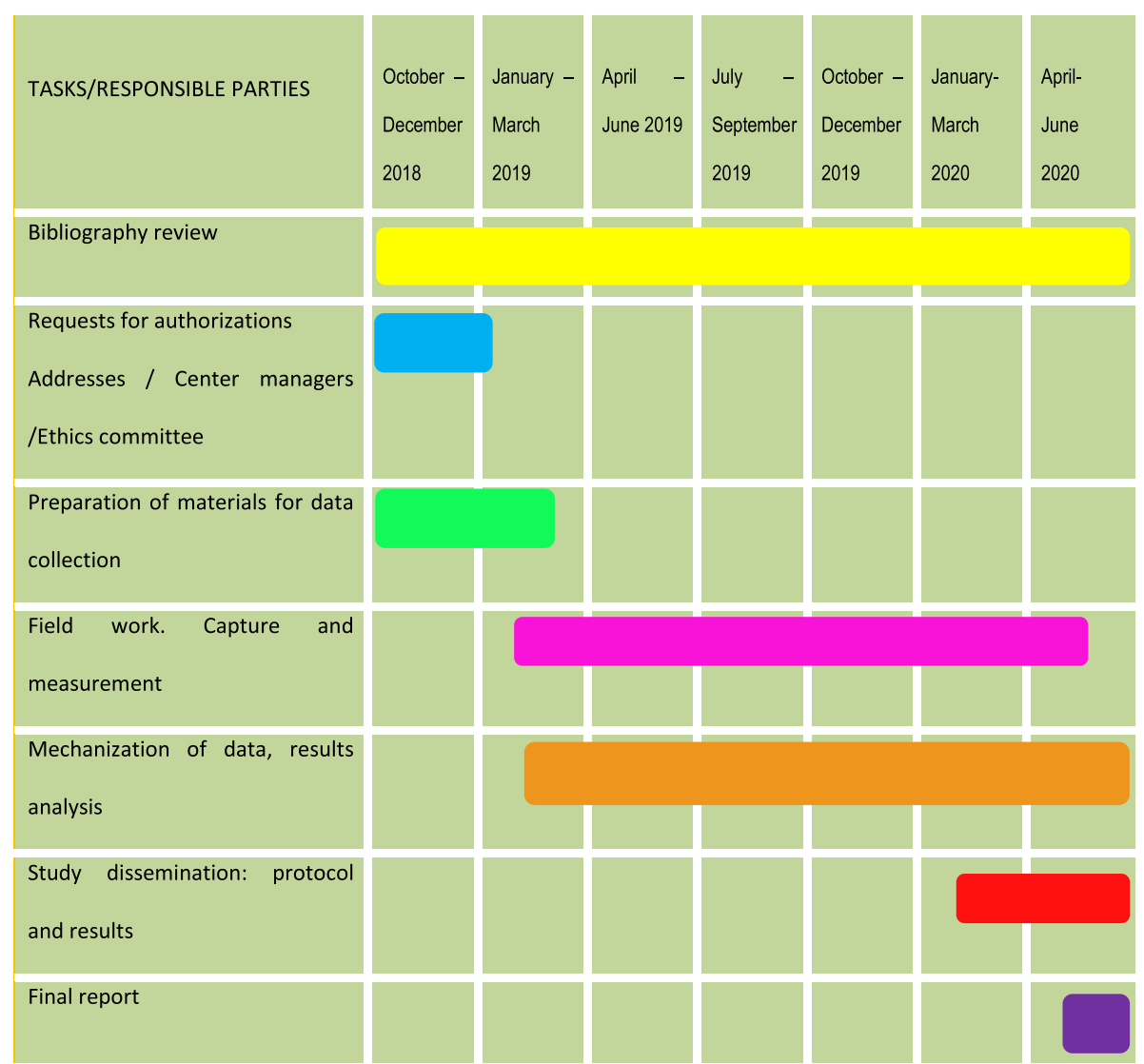

Fig. 2 Gantt's study diagram

\section{Expected results}

For the desirable data following data analysis, the experimental treatment would include the following:

- Reduce the volume of the affected extremity by at least $150 \mathrm{ml}$. more than the control group intervention.

- Positively impact the treated patient's HRQOL, improving the mean scores of the three dimensions from the ULL-27 questionnaire by at least 12.58 points (minimum detectable change).

- Improve the functionality of the upper limbs affected by lymphedema, measured using Quick Dash on at least 15 points.

- Reduce costs by at least $50 \%$ with respect to standard treatments in the respective stage.

\section{Discussion}

The experimental TAPA treatment attempts to incorporate the advantages of comfort with respect to standard treatment by substituting compressive elements for proprioceptive ones, which facilitate the participation of the individuals suffering from the lymphedema in everyday situations.
It is conceptualized as a patient-focused, personalized treatment, in which the significant prescribed activities adapt to each case.

Based on the study's anticipated results, TAPA may result in the creation of the first lymphedema rehabilitation protocol in an upper limb, secondary to breast cancer, which reduces intervention costs.

The recommended occupational therapy contribution based on evidence from lymphedema rehabilitation, suggests the inclusion of the occupational needs of the attended individuals and the adaptation to their everyday surroundings, potentially improving their self-perception of the health-related quality of life.

\section{Abbreviations \\ ADL: Activities of daily living: TAPA: Activity-oriented proprioceptive antiedema therapy (In Spanish: Terapia antiedema propioceptiva orientada a la actividad); BC: Breast cancer; BCRAL: Breast cancer-related arm lymph- edema; CPT: Complex physical therapy; CDT: Complex decongestive therapy; DLT: Decongestive lymphedema therapy; HRQOL: Health-related quality of life; MLD: Manual lymphatic drainage; OT: Occupational therapy; PC: Primary care; PNF: Proprioceptive neuromuscular facilitation element; ROM: Range of motion; TNM: Techniques of neural mobilization}

\section{Acknowledgements}

The authors wish to thank to all of the women participating in the study, and the B21_R17 research group belonging to the Department of Research, 
Innovation and Universities of the Aragon government (Spain), Feder Funds "Another way to make Europe", the TAPA Collaborative Group and physiotherapist Manuela Mejías Ruiz from the Reina Sofía Hospital.

\section{Authors' contributions}

MNM, LAP, JS, AJJ were responsible for the conception and design of the study. MNM, MTM and MVO are responsible for data collection. MNM, LAP, JS, AJJ, MVO, MTM, CB, BO and RM will be responsible for data analysis and will contribute to the interpretation of data. AJV, MVO and MNM wrote the manuscript, which was critically revised by all the other authors. All authors have approved the final version of the manuscript.

\section{Funding}

This project has been granted by Professional College of Occupational Therapists of Extremadura (Spain). This project has been also awarded a financial contribution by the Primary Health Care Research Group of Aragon (GAIAP-B21-17R group), recognized and funded by the Government of Aragon (Spain) and by Feder Funds "Another way to make Europe". The funding source has no direct roles in the design of this protocol, data collection, analysis and interpretation of the data.

\section{Availability of data and materials}

Not applicable.

\section{Ethics approval and consent to participate}

An informed consent document will be requested from each participating subject. The project is approved by the Research Ethics Committee of the Reina Sofía Hospital in Córdoba, in Act No. 282, ref. 4084, of December 27 , 2018 and the authorization of the Management / Direction of the Córdoba and Guadalquivir Health District, the Reina Sofía University Hospital and the AECC.

The principles established in the Declaration of Helsinki, in the Council of Europe agreement on human rights and biomedicine, as well as the requirements established in the Spanish legislation will be respected. It will comply with the rules of good clinical practice (art. 34 RD 223/2004; community directive 2001/20 / EC), the protection of personal data and confidentiality (European Data Protection Regulation, and in accordance with the Organic Law 3/2018 Protection of Personal Data and guarantee of digital rights). In the development of the study, the Patient Autonomy Law 41/2002, and the Biomedical Research Law 14/2007 will be considered.

\section{Consent for publication}

Not applicable.

\section{Competing interests}

The authors declare no conflict of interest.

\section{Author details}

${ }^{1}$ Córdoba and Guadalquivir health district, Andalusia Health Service, Córdoba, Spain. ${ }^{2}$ Andalusia Health Service, Maimonides Institute of Biomedical Research of Cordoba (IMIBIC)/Universidad de Cordoba, Córdoba, Spain. ${ }^{3}$ Valle de los Pedroches Hospital, Pozoblanco, Spain. ${ }^{4}$ Reina Sofia Hospital, Córdoba, Spain. ${ }^{5}$ Institute for Health Research Aragon (IIS Aragon), Zaragoza, Spain. ${ }^{6}$ Aragones Heath Service, Zaragoza, Spain. ${ }^{7}$ University of Zaragoza, Zaragoza, Spain.

\section{Received: 3 June 2020 Accepted: 22 October 2020}

Published online: 09 November 2020

\section{References}

1. Bray F, Ferlay J, Soerjomataram I, Siegel RL, Torre LA, Jemal A. Global cancer statistics 2018: GLOBOCAN estimates of incidence and mortality worldwide for 36 cancers in 185 countries. CA Cancer J Clin. 2018;68(6):394-424 Available from: http://www.ncbi.nlm.nih.gov/pubmed/30207593.

2. Asociación Española Contra el Cáncer (Spanish Association Againts Cancer). Todo lo que Necesitas Saber (All you need to know). Available from: https:// www.aecc.es/es/todo-sobre-cancer/tipos-cancer/cancer-mama. Accessed 13 Mar 2019.

3. Baxter MF, Newman R, Longpré SM, Polo KM. Occupational therapy's role in cancer survivorship as a chronic condition. Am J Occup Ther. 2017;71(3): 7103090010P1-P7.
4. Cuello Villaverde E, Guerola Soler N, López RA. Perfil clínico y terapéutico del linfedema postmastectomía. Rehabilitación. 2003;37(1):22-32 Available from: https://linkinghub.elsevier.com/retrieve/pii/S0048712003733295.

5. Puigdellivol Serafí C, Alonso Álvarez B. Guia de orientación diagnóstica y terapéutica del linfedema [Internet]. 2017. 148 p. Available from: http://www.capitulodeflebologia.org/media/Guia-linfedema-segundaedicion-2017_439.pdf.

6. Teijeiro JFC, Torres MEC, Touza AL, Cuñarro MG, Estévez LP, Varela AS. Prevención del cáncer de mama en atención primaria. Aten Primaria. 2000; 26(6):419-27 Available from: https://www.sciencedirect.com/science/article/ pii/S0212656700786938.

7. María Eugenia Bravo M, Octvio Peralta M, Paulina Neira V, Laura Itriago G. Prevención y seguimiento del cáncer de mama, según categorización de factores de riesgo y nivel de atención. Rev Médica Clín Las Condes. 2015; 24(4):578-87.

8. Loh SY, Musa AN. Methods to improve rehabilitation of patients following breast cancer surgery: a review of systematic reviews. Breast Cancer Targets Ther. 2015;7:81-98.

9. Silver JK, Gilchrist LS. Cancer rehabilitation with a focus on evidence-based outpatient physical and occupational therapy interventions. Am J Phys Med Rehabil. 2011;90(SUPPL.5):5-15.

10. Stout NL, Silver JK, Raj VS, Rowland J, Gerber L, Cheville A, et al. Toward a National Initiative in Cancer rehabilitation: recommendations from a subject matter expert group. Arch Phys Med Rehabil 2016;97(11):2006-2015. Available from: https://doi.org/10.1016/j.apmr.2016.05.002.

11. Morgan P. Best practice for the management of lymphoedema. International consensus. London: The lymphoedema framework; 2006.

12. Alba Conejo E, Alvarez M, Bayo E, Del Río S, Doctor M, Dueñas B, et al. Proceso Asistencial Integrado Cáncer de Mama. [Internet]. Consejería de salud. Junta de Andalucía. 2011 [cited 2019 Sep 12]. 175 p. Available from: https://www.juntadeandalucia.es/export/drupaljda/salud_5af1956e6a064_ mama_deteccion_3e_nuevo.pdf.

13. Jeffs E, Ream E, Taylor C, Bick D. Clinical effectiveness of decongestive treatments on excess arm volume and patient-centered outcomes in women with early breast cancer-related arm lymphedema. JBI Database Syst Rev Implement Rep. 2018;16(2):453-506 Available from: http://insights. ovid.com/crossref?an=01938924-201802000-00015.

14. Preston NJ, Seers K, Mortimer PS. Physical therapies for reducing and controlling lymphoedema of the limbs. Cochrane Database Syst Rev. 2004; (4). [cited 2019 Feb 3] Available from: https://doi.org/10.1002/14651858. CD003141.pub2.

15. Lasinski BB, Thrift KMK, Squire DC, Austin MK, Smith KM, Wanchai A, et al. A systematic review of the evidence for complete decongestive therapy in the treatment of lymphedema from 2004 to 2011. PM R 2012;4(8):580-601. Available from: https://doi.org/10.1016/j.pmrj.2012.05.003.

16. Longhurst E, Dylke ES, Kilbreath SL. Use of compression garments by women with lymphoedema secondary to breast cancer treatment. Support Care Cancer. 2018;26(8):2625-32.

17. Navarro-Brazález B, Sánchez-Sánchez B. El vendaje en el tratamiento fisioterapéutico del linfedema secundario a cancer de mama: Una serie de casos. Fisioterapia 2014;36(1):49-53. Available from: https://doi.org/10.1016/j.ft.2013.03.004.

18. Tambour M, Holt M, Speyer A, Christensen R, Gram B. Manual lymphatic drainage adds no further volume reduction to complete decongestive therapy on breast cancer-related lymphoedema: a multicentre, randomised, single-blind trial. Br J Cancer 2018;119(10):1215-1222. Available from: https://doi.org/10.1038/s41416-018-0306-4.

19. Luctkar-Flude M, Aiken A, McColl MA, Tranmer J. What do primary care providers think about implementing breast cancer survivorship care? Curr Oncol. 2018;25(3):196-205.

20. Lpez-Martn M, De Carlos Iriarte E. El papel de la escuela de linfedema y la cinesiterapia en la prevencin y el tratamiento del linfedema. Rehabilitacion. 2010;44(SUPPL. 1):49-53.

21. Forner Cordero I, Maldonado Garrido D, Muñoz L. Necesidad de información para la prevención del linfedema posmastectomía. Rehabilitación. 2003;37(3):141-4 Available from: http://linkinghub.elsevier. com/retrieve/pii/S004871200373357X.

22. Smoot B, Boyd BS, Byl N, Dodd M. Mechanosensitivity in the upper extremity following breast cancer treatment. J Hand Ther 2014;27(1):4-11. Available from: https://doi.org/10.1016/j.jht.2013.08.021.

23. de la Rosa Díaz I, Torres Lacomba M, Cerezo Téllez E, Díaz del Campo Gómez-Rico C, Gutiérrez Ortega C. Accessory joint and neural mobilizations 
for shoulder range of motion restriction after breast cancer surgery: a pilot randomized clinical trial. J Chiropr Med. 2017;16(1):31-40. Available from: https://doi.org/10.1016/j.jcm.2016.09.001.

24. Boudier-Revéret M, Gilbert KK, Allégue DR, Moussadyk M, Brismée JM, Sizer PS, et al. Effect of neurodynamic mobilization on fluid dispersion in median nerve at the level of the carpal tunnel: a cadaveric study. Musculoskelet Sci Pract. 2017;31:45-51.

25. Ha KJ, Lee SY, Lee H, Choi SJ. Synergistic effects of proprioceptive neuromuscular facilitation and manual lymphatic drainage in patients with mastectomy-related lymphedema. Front Physiol. 2017;8(NOV):1-8.

26. Ha K-J, Choi SJ. Effects of PNF rehabilitation exercise on lymphedema following mastectomy for breast cancer. Med Sci Sport Exerc. 2014;46:368 [cited 2018 Oct 21] Available from: http://https//insights.ovid.com/ crossref?an=00005768-201405001-01115.

27. Hwang WT, Chung SH, Chung MS, Lee KH, Kim T. Effect of proprioceptive neuromuscular facilitation D2 flexion and breathing exercises on lymphedema without a short stretch compression bandage. J Phys Ther Sci. 2015;27(10):3341-3 Available from: https://www.jstage.jst.go.jp/article/jpts/2 7/10/27_jpts-2015-224/_article.

28. Kärki A, Simonen R, Mälkiä E, Selfe J. Impairments, activity limitations and participation restrictions 6 and 12 months after breast cancer operation. J Rehabil Med. 2005;37(3):180-8.

29. Esteban-Vico JR. Villaverde-Dom??nech E, Del Caz DP, Klenner-Mu??oz C, Sim??n-Sanz E. Vendaje autoadherente en el tratamiento integral y rehabilitador de la mano quemada. Cir Plast Ibero-Latinoamericana. 2016; 42(4):347-53.

30. Franks PJ, Moffatt CJ, Murray S, Reddick M, Tilley A, Schreiber A. Evaluation of the performance of a new compression system in patients with lymphoedema. Int Wound J. 2013;10(2):203-9.

31. Moffatt CJ, Franks PJ, Hardy D, Lewis M, Parker V, Feldman JL. A preliminary randomized controlled study to determine the application frequency of a new lymphoedema bandaging system. Br J Dermatol. 2012;166(3):624-32.

32. González Viejo MA, Condón Huerta MJ, Lecuona Navea M, Val Lampreave L, Laínez Zaragüeta I, Rezusta Sagasti L, et al. Coste-efectividad del tratamiento del linfedema postmastectomía en españa. Rehabilitación. 2001;35(2):68-73 [cited 2018 Nov 1] Available from: https://www.sciencedirect.com/science/ article/pii/S004871200173143X.

33. Martínez Jaimez P. Evaluación del riesgo de linfedema. Adaptación española del Wannan Medical College Scoring System. Barcelona: Universitat Internacional de Catalunya; 2017. https://www.recercat.cat/bitstream/ handle/2072/305491/Patricia_Martínez_Jaimez.pdf?sequence=1. Accessed 1 Nov 2018.

34. de Miguel Benadiba C, Martín López de Abajo M, Teixeira Taborda A, Sánchez Tarifa P, Gijón Moreno L. Gestión económica del tratamiento del linfedema. Rev Senol y Patol Mamar. 2016;29(4):157-162. Available from: https://doi.org/10.1016/.senol.2016.06.003

35. Román Lizano CR. Diseño de un programa de linfedema en el Instituto Nacional de enfermedades Neoplásicas de Lima 2017. Lima: Universidad Cesar Vallejo; 2018. http://repositorio.ucv.edu.pe/bitstream/handle/20.5 00.12692/22049/Román_LCR.pdf? sequence=1\&isAllowed=y. Accessed 1 Nov 2018.

36. Zarate V. Evaluaciones económicas en salud: Conceptos básicos y clasificación (Economic evaluations in healthcare: Basic concepts and classification). Rev Med Chile. 2010;138(Supl 2):93-7.

37. Servicio Andaluz de Salud. Rehabilitación y fisioterapia en Atención Primaria. Guía de Procedimientos. Sevilla; Consejería de Salud (Gobierno de Andalucía); 2003. https://www.sspa.juntadeandalucia.es/ servicioandaluzdesalud/sites/default/files/sincfiles/wsas-media-mediafile_ sasdocumento/2019/manualderehabilit\%20\%282\%29.pdf. Accessed 3 Feb 2019.

38. International Society of Lymphology. The diagnosis and treatment of peripheral lymphedema: 2013 Consensus Document of the International Society of Lymphology. Lymphology. 2013;46(1):1-11.

39. Johnson KC, Kennedy AG, Henry SM. Clinical measurements of lymphedema. Lymphat Res Biol 2014;12(4):216-221. Available from: http://online.liebertpub.com/doi/abs/https://doi.org/10.1089//rb.2014.0019.

40. Kizil R, Dilek B, Şahin E, Engin O, Soylu AC, Akalin E, et al. Is continuous passive motion effective in patients with lymphedema? a randomized controlled trial. Lymphat Res Biol. 2018;16(3):263-269. [cited 2019 Feb 3]Available from: http://www.liebertpub.com/doi/https://doi.org/10.1089/rb. 2017.0018.
41. Martín ML, Hernández MA, Avendaño C, Rodríguez F, Martínez H. Manual lymphatic drainage therapy in patients with breast cancer related lymphoedema. BMC Cancer. 2011;11(1):94 Available from: http://www. biomedcentral.com/1471-2407/11/94

42. Arias-Cuadrado A, Lvarez-Vzquez MJ, Martn-Mourelle R, Villarino-Daz JC. Clnica, clasificacin y estadiaje del linfedema. Rehabilitacion. 2010;44(SUPPL. 1):29-34.

43. Romero Cullerés G, Almendáriz JA. Linfedema después de la cirugía por cáncer de mama. Estudio de la incidencia y factores de riesgo en 113 pacientes. Rehabilitación. 2004;38(2):72-7 Available from: http://linkinghub. elsevier.com/retrieve/pii/S0048712004734313.

44. Servicio de Medicina Física y Rehabilitación. Rehabilitación del linfedema. Actualización y protocolo. Medicina (B Aires) [Internet]. 2008;72. Available from: http://www.sld.cu/galerias/pdf/sitios/rehabilitacion/tratamiento_del_ linfedema.pdf.

45. López Martín M, Valencia Álvarez FJ, González González R, Rodríguez Salvanés FJ, Crespo Cobo P, Hernández García MA. Validación de herramienta informática para el cálculo de linfedema en pacientes con afectación unilateral de extremidad superior. Rehabilitación. 2011;45(2):12733 [cited 2019 Feb 3] Available from: https://inkinghub.elsevier.com/ retrieve/pii/S0048712011000375.

46. Hervás MT, Navarro Collado MJ, Peiró S, Rodrigo Pérez JL, López Matéu P, Martínez Tello I. Versión Española del cuestionario DASH. Adaptación transcultural, fiabilidad, validez y sensibilidad a los cambios. Med Clin (Barc). 2006;127(12):441-7.

47. Beaton DE, Wright JG, Katz JN, Amadio P, Bombardier C, Cole D, et al. Development of the QuickDASH: COmparison of three item-reduction approaches. J Bone Jt Surg - Ser A. 2005;87(5):1038-46.

48. Alonso Álvarez B. Cuestionario de calidad de vida ULL-27: un instrumento específico para pacientes con linfedema de miembro superior tras cáncer de mama. Adaptación transcultural y validación de su versión española 2016; Available from: http://eprints.ucm.es/38892/1/T37688.pdf.

49. Herdman M, Badia X, Berra S. El EuroQol-5D: una alternativa sencilla para la medición de la calidad de vida relacionada con la salud en atención primaria. Atención Primaria. 2001;28(6):425-9 Available from: http://inkinghub.elsevier. com/retrieve/pii/S0212656701704064.

\section{Publisher's Note}

Springer Nature remains neutral with regard to jurisdictional claims in published maps and institutional affiliations.

\section{Ready to submit your research? Choose BMC and benefit from:}

- fast, convenient online submission

- thorough peer review by experienced researchers in your field

- rapid publication on acceptance

- support for research data, including large and complex data types

- gold Open Access which fosters wider collaboration and increased citations

- maximum visibility for your research: over $100 \mathrm{M}$ website views per year

At $\mathrm{BMC}$, research is always in progress.

Learn more biomedcentral.com/submissions 